\title{
EVALUATION OF RAINFALL-RUNOFF MODELS FOR MEDITERRANEAN SUBCATCHMENTS
}

\author{
A. Cilek ${ }^{a^{*}}$, S. Berberoglu a C. Donmez ${ }^{\text {a }}$ \\ a Department of Landscape Architecture, University of Cukurova, Adana 01330, Turkey - (acilek, suha, cdonmez)@cu.edu.tr
}

Commission WG VIII/4

KEY WORDS: Runoff, PESERA, hydrology, Mediterranean

\begin{abstract}
:
The development and the application of rainfall-runoff models have been a corner-stone of hydrological research for many decades. The amount of rainfall and its intensity and variability control the generation of runoff and the erosional processes operating at different scales. These interactions can be greatly variable in Mediterranean catchments with marked hydrological fluctuations.

The aim of the study was to evaluate the performance of rainfall-runoff model, for rainfall-runoff simulation in a Mediterranean subcatchment. The Pan-European Soil Erosion Risk Assessment (PESERA), a simplified hydrological process-based approach, was used in this study to combine hydrological surface runoff factors. In total 128 input layers derived from data set includes; climate, topography, land use, crop type, planting date, and soil characteristics, are required to run the model. Initial ground cover was estimated from the Landsat ETM data provided by ESA.

This hydrological model was evaluated in terms of their performance in Goksu River Watershed, Turkey. It is located at the Central Eastern Mediterranean Basin of Turkey. The area is approximately $2000 \mathrm{~km}^{2}$. The landscape is dominated by bare ground, agricultural and forests. The average annual rainfall is $636.4 \mathrm{~mm}$. This study has a significant importance to evaluate different model performances in a complex Mediterranean basin. The results provided comprehensive insight including advantages and limitations of modelling approaches in the Mediterranean environment.
\end{abstract}

\section{INTRODUCTION}

As the term "rainfall-runoff model" suggests, the major input into the model is an estimate of rainfall, and the output is an estimate of runoff. The intermediate steps that transform rainfall to runoff are the model processes. Among the hydrologic processes typically modelled are: interception, infiltration, evapotranspiration, snowpack and snowmelt, retention and detention storages, soil water movement, percolation to ground water, overland flow, open channel flow, and subsurface flow (interflow and base flow) (Knapp et al., 1991).

Models are normally characterized or classified to help describe and discuss their capabilities, strengths, and limitations. There is no universal method to characterize rainfall-runoff models, and models have been classified in several ways depending on the criteria of interest. Different types of rainfall-runoff models are being used by many research institutions, government, organizations and other water related sectors for decision support systems. These models have to be calibrated and thoroughly validated. However, calibrating a rainfall runoff model is not an easy task due to large number of model parameters involved especially in case of distributed rainfall runoff model (Willems, 2009).

In present days, many rainfall-runoff models are extensively using for hydrological analysis worldwide as well as many statistical tools are developed to evaluate the model results. In order to focus on a comparison of models, rainfall-runoff model has been evaluated in this study. This paper aims to help provide the improved understanding of rainfall-runoff models for Mediterranean environment.

\section{MATERIAL AND METHODS}

\subsection{Study Area}

In this paper, Ermenek Subscatchment, Goksu River basin in the Eastern Mediterranean region of Turkey, is selected as the study area. This area has a drainage area of about $2000 \mathrm{~km}^{2}$ with a river length of about $120 \mathrm{~km}$ (Fig. 1). Eastern Mediterranean region of Turkey has a very high local environmental quality and sensitivity in respect to forest ecosystems. The climate is characterized by prevailing Mediterranean with mild and rainy winters and hot and dry summers with a mean annual precipitation of approximately 800 mm (Donmez et al., 2015).

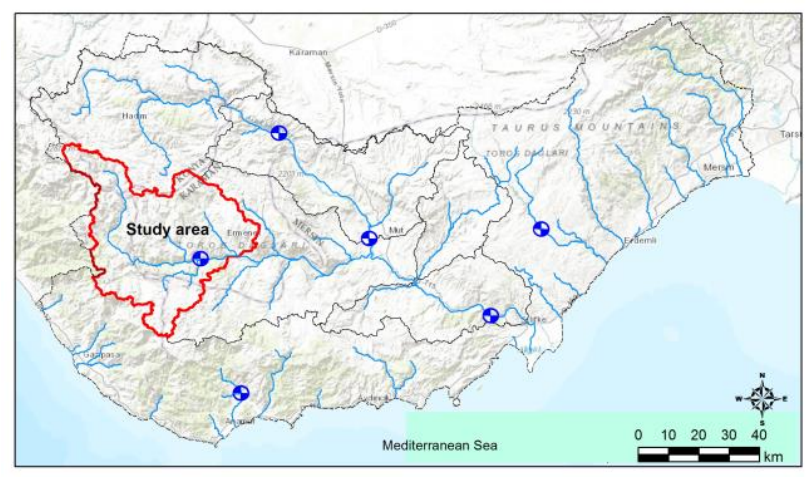

Fig.1. Location of the Ermenek Subcatchment in the Goksu Basin, Turkey

\subsection{Material}

Topographical information is used in hydrological modelling to correct radiance input on sloped units and to determine the drainage network. A Digital Elevation Model (DEM) was

\footnotetext{
* Corresponding author
} 
derived from ASTER and has provided the topographic information to PESERA such as standard deviation of DEM, slope length, aspect and a digital stream network.

Climate data included number of rain days, mean rain per rain day and its standard deviation to provide the distribution of daily rainfalls, temperature (minimum, maximum), potential evapotranspiration obtained from 37-years long record (1975 to 2012) from 16 climate stations around the study area.

Soil types have an important impact on several hydrological processes, like infiltration, evapotranspiration and runoff generation (Donmez et al., 2016). The PESERA model needs information about the soil erodibility, crustability, soil water storage capacity for each soil unit.

\subsection{Methods}

\subsubsection{PESERA Model}

The Pan-European Soil Erosion Risk Assessment (PESERA), a simplified hydrological process-based approach (Kirkby et al., 2008), was used in this study to evaluate hydrological surface runoff. By attempting to use advances in the understanding of runoff processes as opposed to sediment transport, it was only sensible for a forecast of runoff and soil erosion in PESERA to be built on a hydrological core (Kirkby et al., 2008).

A simple storage threshold model is used to convert daily rainfall to daily total overland flow runoff. Sediment transport to the base of the hillside is estimated as the product of soil erodibility and a power law function of runoff discharge and slope gradient. Finally, daily rates of soil erosion are integrated over the frequency distribution of daily rainfalls to estimate long-term average soil erosion rates. (Kirkby et al., 2003; de Vente et al, 2008). The simplest effective tool for estimating runoff is the notion of a threshold storm size. Beneath the threshold there is little or no runoff; above it all or a high proportion of the additional rainfall generates overland flow. Thus the average annual overland flow runoff (per unit area) is estimated as (Kirkby, 2003):

$$
I=\sum_{r>h} f(r) p(r-h)
$$

where the summation is made over all storms, $r$ which exceed the runoff threshold $\mathrm{h}$, $f(r)$ is the frequency of rains of $r$ and $\mathrm{p}$ is the proportion of runoff above the threshold

The runoff threshold and proportion of subsequent runoff are simplifications of cumulative infiltration and runoff curves. Runoff Threshold is estimated from the crown cover, soil organic matter and soil texture/ structure characteristics (Kirkby, 2003).

Figure 2 outlines the hydrological balance within the PESERA model. Precipitation is divided into daily storm events, expressed as a frequency distribution, that drive infiltration excess overland flow and soil erosion, and monthly precipitation, some of which may be as snow, driving saturation levels in the soil. Infiltration excess overland flow runoff is estimated from storm rainfall and soil moisture. Sediment transport is then estimated from overland flow and routed, in principle, downslope. To obtain long-term estimates of soil erosion these estimates must then be scaled up by integrating over time. This process of scaling up has two stages; first from momentary to event-integrated dependence, and secondly from events to long-term averages via the frequency distribution (Kirkby et al, 2010; Cilek et al. 2015).

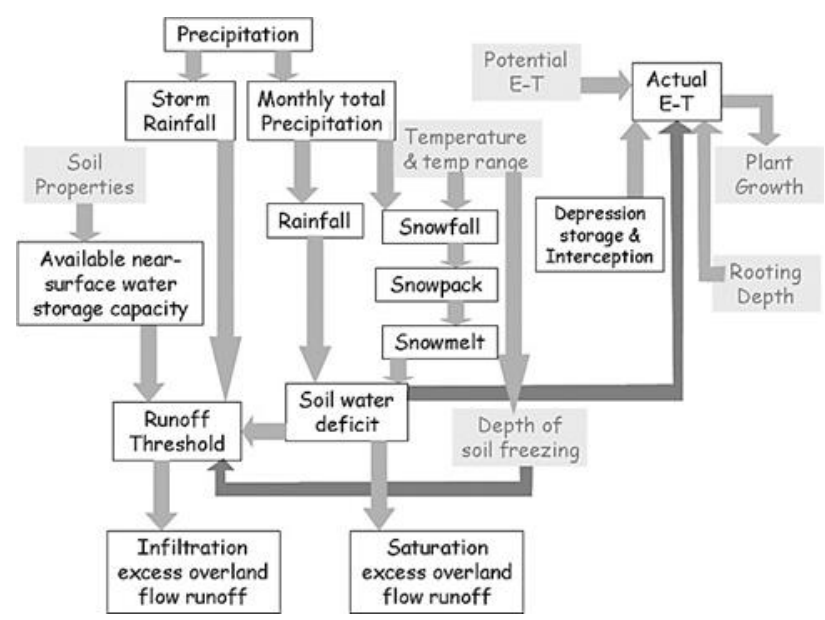

Figure 2. Schematic hydrological sub-model within the PESERA model (Kirkby et al. 2010).

\section{RESULTS}

The aim of the study was to estimate the spatial variability of surface runoff using PESERA model and remote sensing techniques in Ermenek subcatchment where climate is characterized by prevailing Mediterranean watershed, Turkey. In this paper, the results of annual, monthly surface runoff provided by PESERA model were discussed.

\section{Land Use/Cover map}

The land use/cover map required for the modelling process to estimate surface runoff was produced using LANDSAT ETM scenes acquired 2012, topographical maps and ground truth (Figure 3).

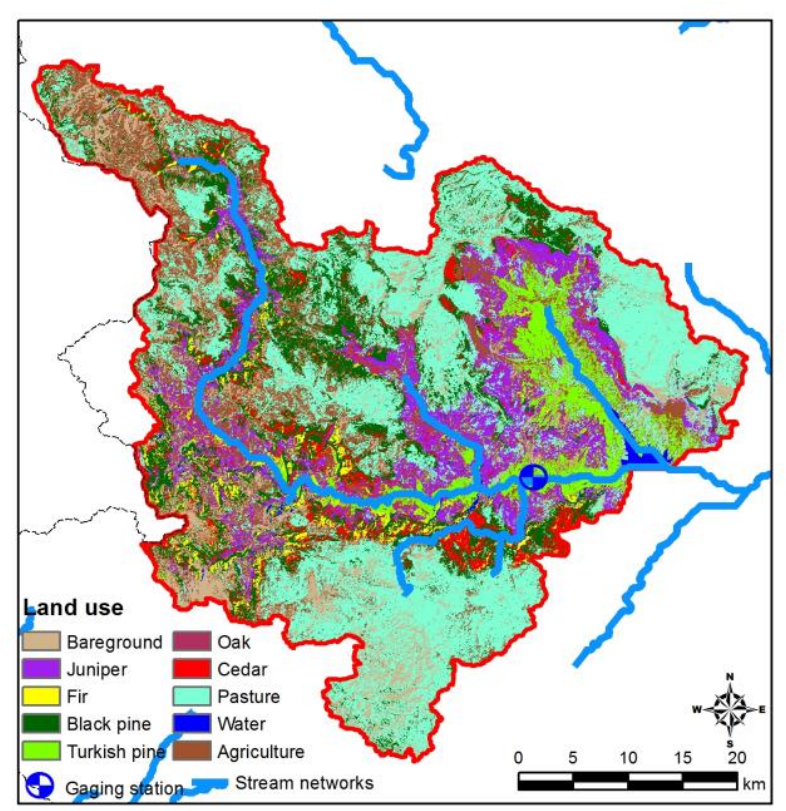

Figure 3. Land use map of the study area 
A high-resolution DEM in $30 \mathrm{~m}$ was derived from ASTER DEM image to run watershed analysis including standard deviation of DEM, slope length, aspect and a digital stream network (Figure 4).

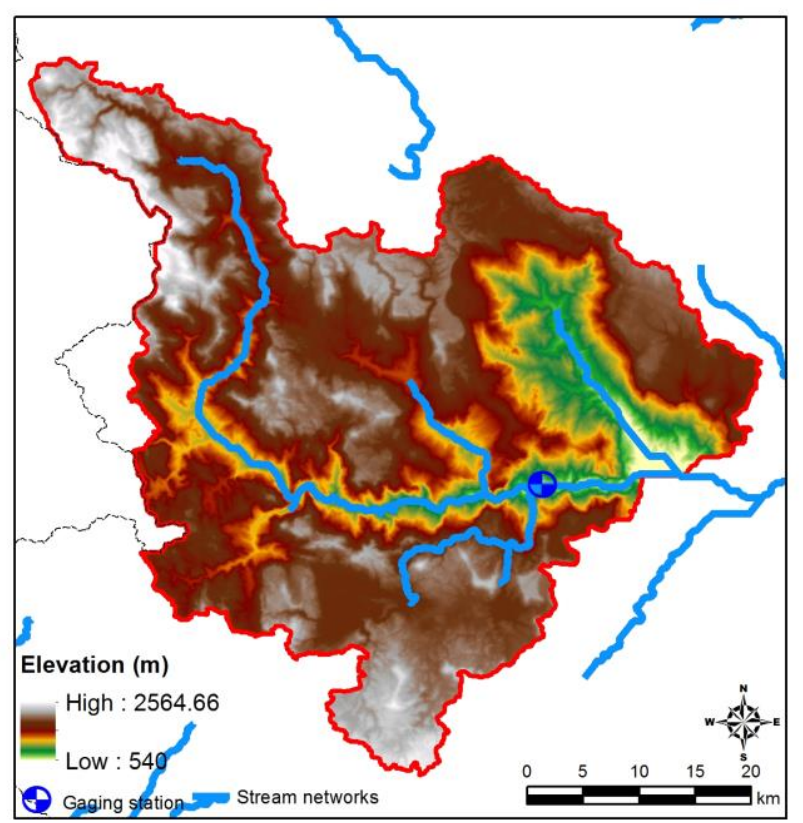

Figure 4. Digital elevation model of the study area

\section{Climate}

The Climate database provided daily time series (1975-2011) from 16 hydro meteorological stations including rainfall, temperature and potential evapotranspiration were interpolated to a $30 \mathrm{~m}$ grid for study area using thin plate smoothing splines methods. The total annual rainfall data were given for an example in Figure 5.

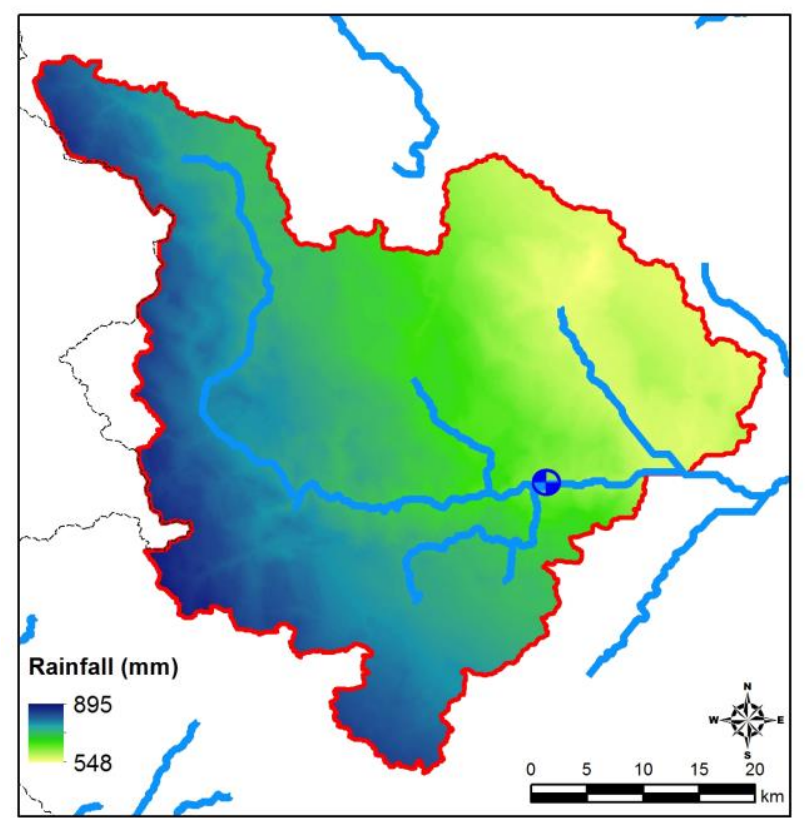

Figure 5. Total annual rainfall map of the study area

Figure 6 shows the distribution of estimated surface runoff for the PESERA model. The highest surface runoff was observed in
November as the lowest one was in August where rainfall was slightly. It shows that a significant increase was determined from October when rainfall intensified. On the other hand, there was a sharp decrease of surface runoff in May in the study area. (Figure 10).
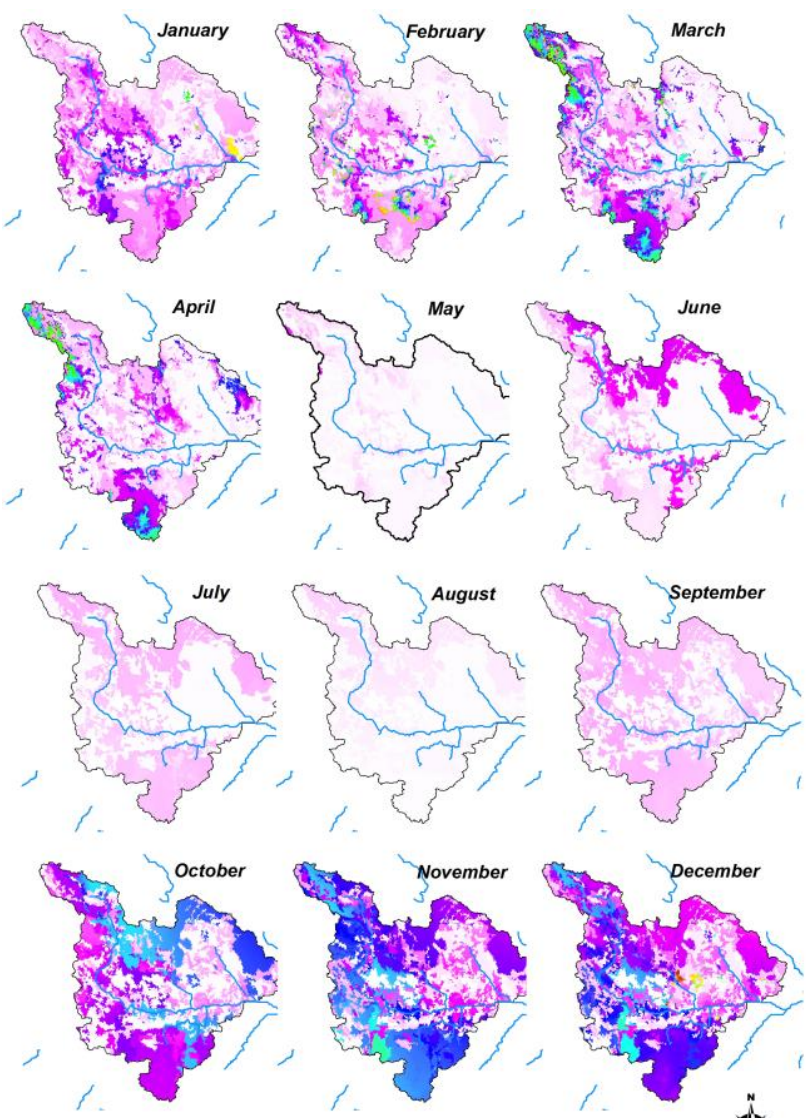

Runoff (mm)
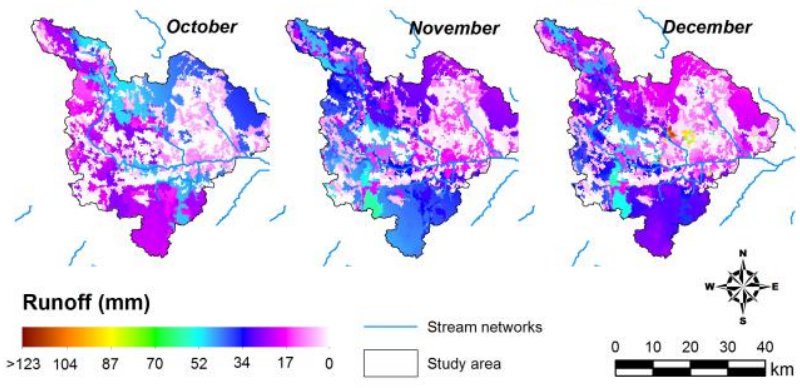

Figure 6. Monthly surface runoff maps derived from the PESERA Model

Monthly surface runoff maps represented the spatial changes of surface runoff in Ermenek Subcatchment during a hydrological year. Surface runoff showed a significant increase during fall season in parallel to increasing rainfall. Summer months showed dry conditions within a significant water deficit that might affect the vegetation distribution remarkably.

Annual and monthly surface runoff was also estimated using PESERA model within the study. The results of the surface runoff analysis on monthly basis were presented in Table 1. 
Table 1. Estimated monthly rainfall and surface runoff results of the study area

\begin{tabular}{lrr|rr}
\hline \multirow{2}{*}{ Months } & \multicolumn{2}{c|}{ Rainfall } & \multicolumn{2}{c}{ Surface Runoff } \\
\cline { 2 - 5 } & \multicolumn{1}{c}{$\left(\mathrm{mm}^{*-1} \mathrm{~m}^{-1}\right)$} & $\left(\mathrm{km}^{3 *} \mathrm{yr}^{-1}\right)$ & $\left(\mathrm{mm}^{*} \mathrm{~m}^{-1}\right)$ & $\left(\mathrm{km}^{3 *} \mathrm{yr}^{-1}\right)$ \\
\hline Mean & Total & Mean & \multicolumn{1}{c}{ Total } \\
\hline January & 110.78 & 220.13 & 8.70 & 17.28 \\
February & 90.13 & 179.09 & 7.56 & 15.02 \\
March & 80.01 & 158.97 & 13.32 & 26.47 \\
April & 49.27 & 97.89 & 9.86 & 19.60 \\
May & 41.02 & 81.51 & 1.52 & 3.03 \\
June & 17.51 & 34.80 & 5.28 & 10.48 \\
July & 7.23 & 14.37 & 2.87 & 5.70 \\
August & 1.77 & 3.52 & 0.85 & 1.69 \\
September & 6.33 & 12.58 & 3.93 & 7.81 \\
October & 51.25 & 101.84 & 19.48 & 38.71 \\
November & 120.20 & 238.84 & 24.43 & 48.53 \\
December & 135.48 & 269.19 & 20.80 & 41.33 \\
\hline TOTAL & 710.99 & 1412.74 & 118.59 & 235.64 \\
\hline
\end{tabular}

According to the initial results, several components can have a potential environmental impact. The highest magnitude of rainfall was during the winter period. The highest rainfall magnitude in December with $135.48 \mathrm{~mm} / \mathrm{m}$. Otherwise, August has the lowest rainfall with $1.7 \mathrm{~mm} / \mathrm{yr}$. Overall, the annual rainfall is around $710.99 \mathrm{~mm}$ on average.

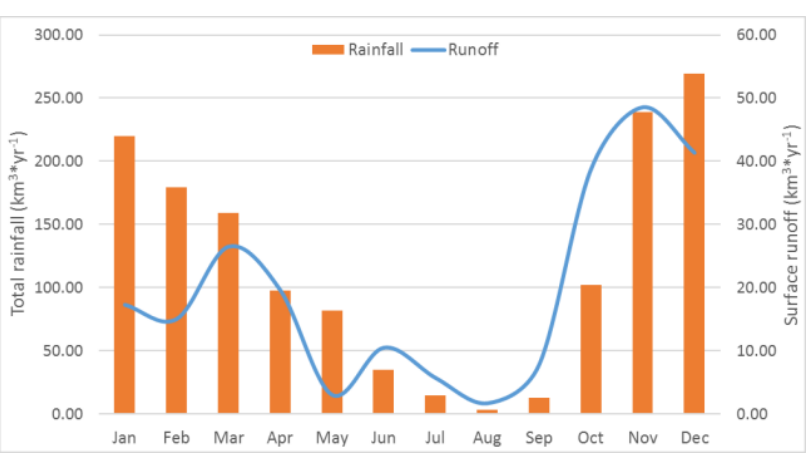

Figure 7. Rainfall- surface runoff simulation for the PESERA model

The monthly estimates of surface runoff increased from October to December during the autumn season in the entire subcatchment, due to heavy rain and high runoff. However, there was a sharp decrease in surface runoff during the winter season. This is because, temperature dropped below zero and rainfall turned to snow. After melting the snow, surface runoff steadily increased especially March and April. Slight changes in surface runoff were realised from May to August until a dramatic increase occurred in June. The PESERA surface runoff estimates range approximately from 1.69 to $48.53 \mathrm{~km}^{3} / \mathrm{yr}$ Overall of the results, the annual surface runoff was around $235.64 \mathrm{~km}^{3} / \mathrm{yr}$, which account for $17 \%$ of the rainfall in the entire subcatchment.

\section{DISCUSSION}

The PESERA model was applied to the Ermenek subcatchment, which includes a gauging station at the downstream. The aim of this study was to incorporate spatial rainfall and remote sensing data to provide enhanced information for the modelling of spatio-temporal surface runoff in a semi-arid Mediterranean environment. The results showed that model was relatively sensitive. In general, the model was feasible for rainfall-runoff process simulation accurately in a complex semi-arid catchment. PESERA is expected to perform accurately with more gauging station data during calibration process of the model, to estimate long time-series of river discharge at the daily scale in Goksu and similar basins of the Mediterranean region.

\section{ACKNOWLEDGEMENTS}

We would like to acknowledge the research project grants (project no: 110Y338 and 114Y273) from the Scientific and Technological Research Council (TUBITAK) of Turkey and the Scientific Research Project Administration Units of Cukurova University (project no: ZF2012Y1).

\section{REFERENCES}

Cilek, A., Berberoglu, S., Kirkby, M., Irvine, B., Donmez, C., and Erdogan, M. A., 2015. Erosion Modelling In A Mediterranean Subcatchment Under Climate Change Scenarios Using Pan-European Soil Erosion Risk Assessment (PESERA), Int. Arch. Photogramm. Remote Sens. Spatial Inf. Sci., XL7/W3, 359-365, doi:10.5194/isprsarchives-XL-7-W3-359-2015, 2015.

de Vente, J., Poesen, J., Verstraeten, G., Van Rompaey, A., and Govers, G., 2008. Spatially distributed modelling of soil erosion and sediment yield at regional scales in Spain. Global and Planetary Change, 60 (3-4), 393-415.

Donmez C., Berberoglu S., Cilek A. 2016. Understanding Spatial and Temporal Snow Dynamics of a Mediterranean Catchment Using Process-Oriented Modelling and Remote Sensing. Fresenius Environmental Bulletin, Vol. 25; No. 1

Donmez, C. and Berberoglu S. 2016. A Comparative Assessment of Catchment Runoff Generation and Forest Productivity in A Semi-Arid Environment. International Journal of Digital Earth. In press.

Donmez, C., Berberoglu, S., Erdogan, M.A., Tanriover, A.A., and Cilek, A. 2015. Response of the regression tree model to high resolution remote sensing data for predicting percent tree cover in a Mediterranean ecosystem. Environ Monit Assess 187:4151. DOI:10.1007/s10661-014-4151-5

Kirkby, M.J., Gobin, A., and Irvine, B. 2003. Pan European Soil Erosion Risk Assessment. Deliverable 5: PESERA Model Strategy, Land Use and Vegetation Growth, European Soil Bureau. http://eusoils.jrc.it/.

Kirkby, M., 2003. Modelling erosin-the PESERA project. In Briefing Papers of the First SCPAE Workshop in Alicante (ES), 14-16 June 2003, Bois Fayos C, Dorren L, Imeson A (eds). SCAPE, IBED. University of Amsterdam, Amsterdam; 15-20.

Kirkby, M.J., Irvine, B., Poesen, J., Borselli, L., Reed, M. (2010). 'Improved process descriptions integrated within the PESERA model in order to be able to evaluate the effects of potential prevention and remediation measures' DESIRE Report 75 D5.2.1

Knapp, H.V., Durgunoglu, A. and Ortel, T.W., 1991. A review of rainfall-runoff modelling for stormwater management. Illinois State Water Survey Hydrology Division, SVS Contract Report 516. pp.96. 
Willems, P., 2009. A time series tool to support the multicriteria performance evaluation of rainfall-runoff models. Environmental Modelling and Software 24(3), pp. 311-321.

\section{APPENDIX}

Any additional supporting data may be appended, provided the paper does not exceed the limits given above. 